\title{
The Expanding Role of
}

\section{Ocean
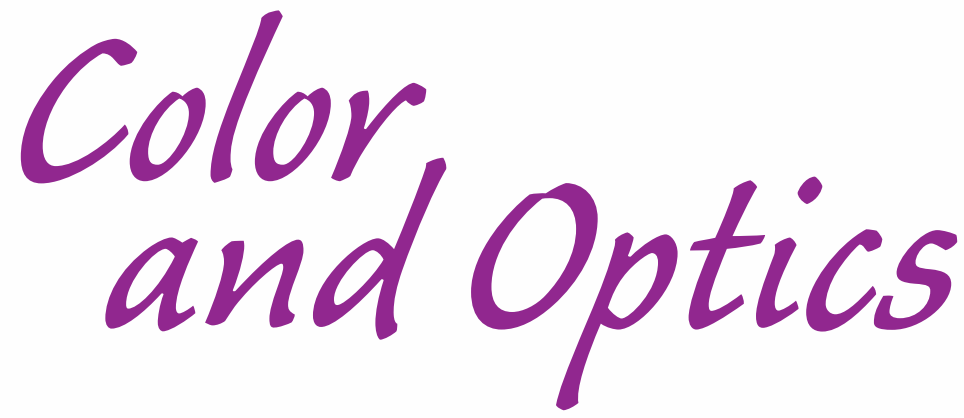

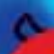

\section{in the Changing Field of Operational Oceanography}

BY SCOTT GLENN, OSCAR SCHOFIELD, TOMMY D. DICKEY, ROBERT CHANT, JOSH KOHUT, HERVÉ BARRIER,

JENNIFER BOSCH, LOUIS BOWERS, ELIZABETH CREED,

CHIP HALDEMAN, ELI HUNTER, JOHN KERFOOT,

CHHAYA MUDGAL, MATTHEW OLIVER, HUGH ROARTY,

EMMELINE ROMANA, MIKE CROWLEY, DONALD BARRICK, AND CLAYTON JONES 


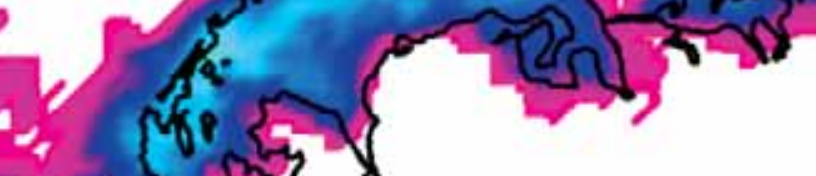
and

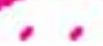

Ocean observatories are changing the way oceanographers go to sea. The rapidly evolving field of ocean optics is producing new technologies and analysis procedures that are contributing to this transition. Optical oceanography is now moving beyond the slowboat approach of stopping to collect discrete profiles and water samples for later laboratory analysis. These traditional methods often require filtering of discrete samples or even solvent extractions, which are time consuming and challenging to use when at sea. Older submersible spectral radiometers had slow scanning speeds, requiring the instrument to be held at constant depth while taking a measurement.

Significant advances in optical instrumentation have now made some optical measurements as easy and robust as those available from physical sensors. Optical sensors are now commonly comingled with the usual mix of temperature, salinity, and current sensors on profilers, moorings, and autonomous platforms. Remote sensing of ocean color by satellites and aircraft is becoming as commonplace as sea surface temperature imagery and satellite altimetry. Physical oceanographers are now using optical measurements as a tool for identifying Lagrangian particles (particles that move with the fluid) to enable more definitive interpretations

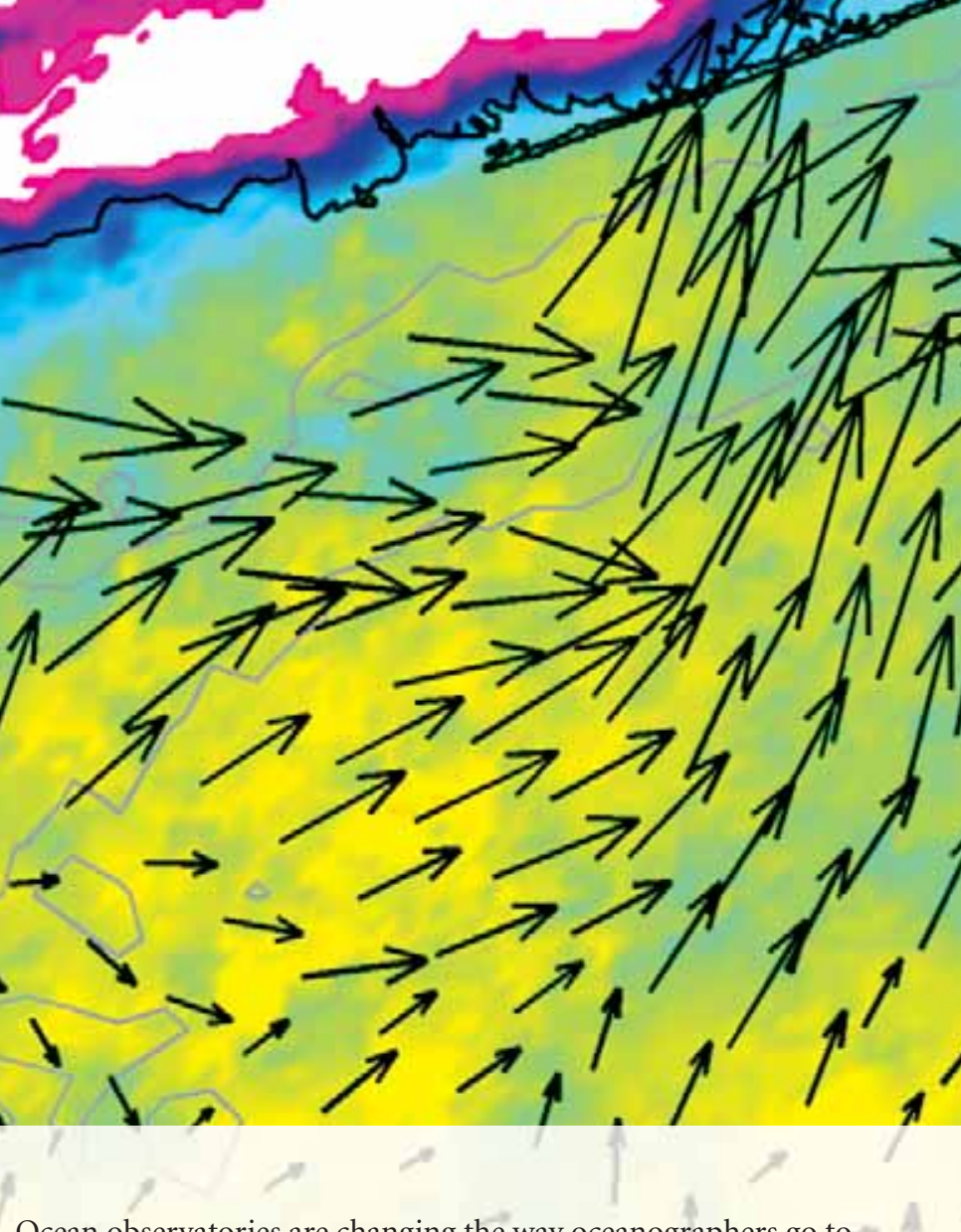
ocean color and optics are ready for the same status in operational oceanography that physical oceanography has enjoyed for decades?

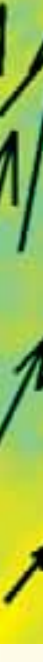




\section{OPERATIONAL OCEANOGRAPHY}

What do we mean by "operational oceanography" today? We know it is very different from traditional expeditionary science conducted on a research vessel. Beyond that, there is little agreement. The term "operational" often implies concepts that include, but are not limited to, a sustained effort beyond the normal grant-funded process study; technologies that are sufficiently robust that they do not require the original developer to operate the system or quality control the results; and quality-controlled, real-time data or derived-products that are distributed to the broader scientific community and the public. However, the interested reader searching for a specific definition will find, not surprisingly, that the definitions vary from operator to operator. "Operational" in this paper will simply refer to sustained data collection or modeling efforts that include real-time distribution of useful products to a larger community, scientific or otherwise.

Within our inclusive definition, the nature of the operational oceanographic community is changing. At one time, operational et al., 2000a). The goal of many ocean observatories is to collect continuous, real-time data over years to decades that can provide a clearer vision of the temporal and spatial evolution of oceanic events as well as identify and document long-term trends. (Glenn et al., 2000b). These observatories thus fit within the inclusive definition of "operational" oceanography.

The number of ocean observatories is growing (e.g., see the list at http://csc.noaa. gov/coos), and they have several things in common. Many of the operational programs have both research and applied objectives, enabling them to access multiple funding sources and create a more diverse, and therefore sustainable, support portfolio. At those supported mostly through peer-reviewed research funds, the long-term data sets often provide a context for specific scientific process studies. Publication of these data in peer-reviewed journals becomes another form of quality control. Yet many of the primarily research-funded observatories also support vital education and outreach components. These observatories are often operated and maintained by groups at state uni-

\section{Optical-sensing techniques will be at the forefront of providing the data to make required ecosystem assessments.}

oceanography in the United States meant, primarily, the U.S. Navy or National Oceanic and Atmospheric Administration (NOAA) in terms of numbers, with smaller, but highly innovative, industry components like those supporting oil and shipping interests. The greatest change in the operational community over the last decade is the emergence and rapid increase in the number of ocean observatories, many of which are coordinated and run by academic institutions (Glenn versities where the research, education, and outreach goals map well onto the primary missions and long-standing traditions of our nation's network of public universities. Most operational programs emphasize realtime data collection, product generation, and distribution of data and products free of charge to a broad community. In addition, many of these observatory efforts have withstood the test of time. Some have operational histories now measured in decades, and even more appeared after the National Ocean Partnership Program (NOPP) began funding academic, industry, and government observatory partnerships in 1998. These new ocean observatories are leading the efforts to transition optical measurements into the operational community.

Optics has been embraced by the new observatories because they are often interdisciplinary, and therefore, strive to serve the needs of biological, chemical, and geological oceanographers as well as physical oceanographers. Optics is one of the few non-invasive means to sample the biological, chemical, or sediment constituents within ocean flows. While optical techniques had been the research bread and butter for a few select laboratories, technological advances have enabled scientists who are more interested in results and interpretation to make the same measurements.

Making an optical measurement in the ocean is no longer a science focus on its own. For example, ocean-color remote sensing had been a research focus for the $\mathrm{Na}$ tional Aeronautics and Space Administration (NASA). NASA's Coastal Zone Color Scanner (CZCS) provided fundamental insights into ocean productivity, paving the way for many subsequent ocean-color satellites to be launched by many countries. As the new millennium begins, the newest generation of U.S. ocean color satellites will likely be maintained by the operational arm of NOAA and not by NASA, which is a research-focused agency.

The research focus using optical measurements is shifting from global deepwater calibration of a single U.S. satellite overpass per day to local calibration and use of multiple overpasses of international satellites to track more rapidly evolving coastal features. For in situ measurements, optical instruments with biofouling protection are now sufficiently 
robust to be deployed for months at time. For example, scientists currently maintain moored observations of Inherent Optical Properties (IOPs) as part of the long-term continuous data streams collected at the Bermuda Testbed Mooring (BTM; Dickey et al., 1998; Dickey et al, 2001; Dickey, 2003) and as part of the operational mooring array in the Gulf of Maine Ocean Observing System (GoMOOS). Ten years ago, making IOP measurements was a research focus unto itself. A developing research direction now is the miniaturization of the same shipboard and moored sensors for long-term deployments on drifting and propelled autonomous platforms (Rudnick and Perry, 2003).

Given the success of optics in research ocean observatories, how will the rapidly expanding optical capabilities be integrated within the evolving structure of U.S. operational oceanography? Multi-use (both scientific and applied) operational observatories have many advantages for rapidly incorporating and transitioning new technologies. Many U.S. Navy interests are beyond our borders, often in denied-access areas, thus U.S. observatories can be used to develop and "sea-truth" sensors and systems locally before demonstrating the new technologies globally. Recently, homeland security issues have become paramount, often requiring technologies similar to those used by the Navy (e.g., optical sensors for in-water detection and identification) to secure U.S. harbors. Scientists researching global climate change, and its potential effect on our heavily used coastal zones, will use long-term observatory data sets that include optics to determine cross-shelf transport pathways between our estuaries and the deep ocean. The recently released draft U.S. Commission on Ocean Policy report has called on operational agencies, such as NOAA, to provide for effective stewardship and management of the oceans that are so critical to the health of the U.S. economy. Optical-sensing techniques will be at the forefront of providing the data to make required ecosystem assessments.

\section{COLLABORATIVE OCEANOGRAPHY: HyCODE}

In the process of promoting environmental stewardship, scientists have realized that many of the big problems in ocean science, and its applications, are interdisciplinary. In the future, these problems need to be addressed with collaborative teams (Ofiara and Seneca, 2001) rather than by individual scientists working within their own specialty. The need for a multidisciplinary research team was clear while trying to understand the dynamic evolution of ocean color in turbulent coastal waters during the U.S. Navy's Hyperspectral Coastal Ocean Dynamics Experiments (HyCODE). During HyCODE, it was necessary for investigators collecting physical (atmospheric and oceanic) and optical (remote sensing and in situ) data to work with each other to improve the understanding of both disciplines. The collaborative environment attracted approximately 200 researchers and students each field season. HyCODE demonstrated the value of a "collaboratory," increasing scientific participation by an order of magnitude and promoting synergies among projects well beyond expectations at the proposal stage (Glenn and Schofield, 2003). Moreover, HyCODE prompted us to push our own operational observatory to larger spatial scales. The highly instrumented 30 km x 30 km Long-term Ecosystem Observatory (LEO) research area off the New Jersey coast was already doing a good job of addressing its goal — to better understand the physical processes leading to the recurrent coastal upwelling centers observed in the local Eulerian (i.e., using stationary platforms
Scott Glenn (glenn@imcs.rutgers.edu) is Professor, Rutgers University Coastal Ocean Observation Lab, New Brunswick, NJ, New Brunswick, NJ. Oscar Schofield is Associate Professor, Rutgers University Coastal Ocean Observation Lab, New Brunswick, NJ. Tommy D. Dickey is Professor, Ocean Physics Laboratory, University of California, Santa Barbara, Goleta, CA. Robert Chant is Assistant Professor, Rutgers University Coastal Ocean Observation Lab, New Brunswick, NJ. Josh Kohut is Project Manager, Rutgers University Coastal Ocean Observation Lab, New Brunswick, NJ.

Hervé Barrier is Research Programmer, Rutgers University Coastal Ocean Observation Lab, New Brunswick, NJ. Jennifer Bosch is Marine Scientist, Rutgers University Coastal Ocean Observation Lab, New Brunswick, NJ. Louis

Bowers is Graduate Student, Rutgers University Coastal Ocean Observation Lab, New Brunswick, NJ. Elizabeth Creed is Marine Engineer, Rutgers University Coastal Ocean Observation Lab, New Brunswick, NJ. Chip Haldeman is Marine Technician, Rutgers University Coastal Ocean Observation Lab, New Brunswick, NJ.

Eli Hunter is Research Programmer, Rutgers University Coastal Ocean Observation Lab, New Brunswick, NJ. John Kerfoot is Marine Scientist, Rutgers University Coastal Ocean Observation Lab, New Brunswick, NJ. Chhaya Mudgal is Research Programmer, Rutgers University Coastal Ocean Observation Lab, New Brunswick, NJ.

Matthew Oliver is Graduate Student, Rutgers University Coastal Ocean Observation Lab, New Brunswick, NJ. Hugh Roarty is Coastal Engineer, Rutgers University Coastal Ocean Observation Lab, New Brunswick, NJ. Emmeline Romana is Project Coordinator, Rutgers University Coastal Ocean Observation Lab, New Brunswick, NJ. Mike Crowley is Science Applications Specialist, SeaSpace Corporation, Poway, CA. Donald Barrick is President, CODAR Ocean Sensors, Los Altos, CA. Clayton Jones is Project Engineer, Webb Research Corporation, E. Falmouth, MA. 
such as moorings to collect data) reference frame (e.g., Chant et al., in press). However, HyCODE was asking coupled physical/biological/geological questions that required answers in a Lagrangian frame (i.e., one that moves with the fluid, with measurements taken over a broader region by gliders and drifters).

\section{Operational sensors on the glider platforms have enabled the}

\section{sensing of particle loads that can then be used to visualize complex flow fields, providing physical oceanographers an additional tool for studying the range of processes active on the continental shelf.}

The most important scientific questions to be answered at the LEO area concerned the observed event-driven changes: are the changes we see in our optical observations of the biological and sediment characteristics due to local processes or advection? Answering this question required us to take a better look at the far field, beyond our now-familiar research area, to try to determine the source of particles and phytoplankton, and how they evolved. We found that even the addition of a research vessel from the UNOLS fleet with scientists carrying out specific sampling plans, designed jointly with the modelers, was not sufficient to satisfy the modelers' need for spatial data to better define regional transport pathways (Wilkin et al., submitted). Thus, during the HyCODE years, development work expanded beyond the successful improvements to physical/optical moorings and bottom tripods (Eulerian instruments) and focused on new sustainable technologies that could provide more frequent coverage over larger spatial scales for longer time periods (to promote the better definition of Lagrangian transport pathways). Three specific spatial technologies were targeted: (1) acquisition of ocean-color
(Curtin et al., 1993) with payload bays for both physical and optical sensors to provide subsurface physical/bio-optical data over larger areas. The result was a new operational observatory that emerged during the HyCODE project: the New Jersey Shelf Observing System (NJSOS) (Schofield et al., 2002). In the spirit of this special issue, we report here some intriguing scientific results, and provide forward-looking comments to prompt discussion.

OPERATIONAL STATUS OF THE NEW JERSEY SHELF OBSERVING SYSTEM

NJSOS is a sustained academic observatory operated by the Rutgers University Coastal Ocean Observation Lab (R.U. COOL) with research, education, and outreach goals consistent with its home base within the State University of New Jersey. In the successful tradition of NOPP, the three spatial sampling technologies listed above are continuously improved and supported through long-standing industry partnerships with SeaSpace, CODAR Ocean Sensors, and Webb Research. In ongoing discussions with numerous scientific, business, and government users, ten scientific questions have emerged for NJSOS (Glenn and Schofield, 2004). Common threads running through many of these questions all concern tracking water masses, and can be generalized as: (a) What is in the water? (b) Where is it going? (c) Where is it going to be in the future when I want to find it so that I can see how it changed? These are essentially the same questions asked by HyCODE scientists, and as in HyCODE, in situ optical measurements and ocean color play a crucial role. Satellite ocean-color imagery from the international constellation and in situ optical sensors on autonomous gliders and moorings, using algorithms and sensors developed through projects that include HyCODE, tell us what is in the water. CODAR surface currents combined with autonomous underwater gliders, both tested during HyCODE, tell us where the water is going. Statistical models and data assimilative ocean-prediction models, with coupled biological or sediment transport models, systems experimented with during HyCODE, provide estimates of where the water will be tomorrow so we can find it, sample it, and see how the particles in it have changed.

Optical measurements, coupled with hydrographic measurements, will significantly improve the tracking of water masses and plumes. Water mass tracking is important for applications that include, for example, tracking of harmful algal blooms, hazardous material spills, and outflow plumes. For nearly a century, hydrographic parameters, such as temperature and salinity, have been used to track water masses over broad oceanographic scales (Helland-Hansen, 1916). Emerging sensors that measure optical parameters such as absorption and backscatter in the water column will provide a means to identify and map water masses and, potentially, determine the composition of the material in the water mass (Tomczak, 
1999). By combining traditional hydrographic data with optical measurements, more parameters are available to define specific water masses and potentially identify them with a source region. Strategies to do this are now being developed using the operational data sets from NJSOS.

The operational status of the observation network, left in place along the New Jersey Shelf at the end of the HyCODE program, illustrates how satellites, CODAR, and gliders can act together to establish what is in the water and where it is going. These three platforms provide the crucial spatial information that someday may enable coupled transport and transformation models to better predict where these water parcels will be and how they changed along the way.
Figure 1 displays a two-year average surface current field from CODAR data. The usual assumption that the depth-averaged shelf currents are $5 \mathrm{~cm} / \mathrm{sec}$ alongshore to the southwest clearly is not true for surface currents. Consequently, even if this canonical view is correct, cross-shelf transport of material in the surface layer would fundamentally differ from that associated with depth-averaged quantities. Instead, a rich and coherent surface current field is evident that includes two cross-shelf transport pathways. One begins in the vicinity of the Hudson River plume, progresses southeast along the southern side of the Hudson Shelf Valley, then turns due south near the $60 \mathrm{~m}$ isobath. The surface layer then encounters a similar southeastward pathway that begins

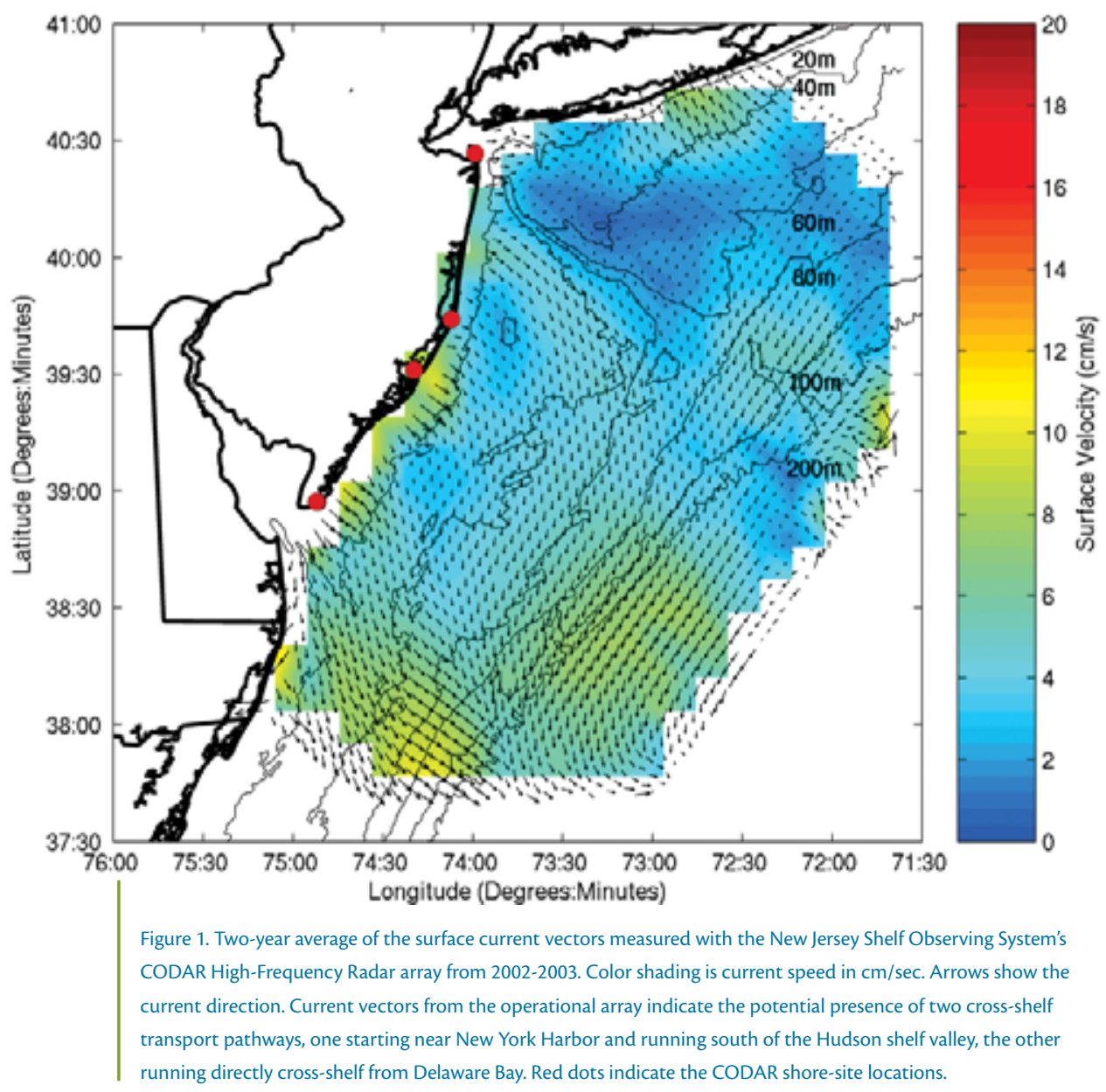

at the entrance to Delaware Bay and progresses directly across the shelf. The Hudson Shelf Valley, a known location of preferred up-canyon bottom transport (Harris et al., 2003), exhibits relatively weak average surface currents.

Does the average current field observed by the CODAR array represent a possible cross-shelf transport pathway for material delivered to the continental shelf by the Hudson plume? Ocean optics will play a central role in answering this question over the next several years. Scientists will first need to identify the plume and then track it over time. In the Hudson plume, sediment particles tend to fall out of suspension quickly near the mouth of the harbor, but high colored dissolved organic matter (CDOM) concentrations are found to be an excellent tracer of the plume for distances of over $100 \mathrm{~km}$ downstream (Johnson et al., 2003). Furthermore, these enhanced CDOM concentrations can be detected in the 440 $\mathrm{nm}$ wavelength visible satellite imagery (e.g., Figure 2 for October to November, 2003). In Figure $2 \mathrm{a}$, the six-day average current field is overlaid on the same six-day composite satellite sea surface temperature (SST) image. The most notable feature is the jet of southward-flowing cold water along a similar mid-shelf transport pathway identified in the Figure 1 average CODAR field. During this six-day period, one very clear MODIS (MODerate Resolution Imaging Spectroradiometer) satellite overpass is available on October 30. The MODIS Normalized Water Leaving Radiance (NWLR) at $443 \mathrm{~nm}$ reflectance product is plotted in Figure 2b, again with the six-day average currents overlaid. The mid-shelf jet is observed to also be a region of low NWRL at this wavelength. Low NWRL could be ascribed to high chlorophyll (phytoplankton), detritus, or CDOM concentrations. Note that CDOM is dissolved in 
the water and thus scatters little light, while phytoplankton and detritus are particles, which scatter light better. Also, note that a similar region of low reflectance is observed in a nearshore band. These satellite maps can now be complemented with optical data from moorings and autonomous vehicles (see Figure 3 in Schofield et al., this issue) to better determine the cause for the reduced NWLR both nearshore and at midshelf.

Figure 3 shows cross-shelf vertical sections of temperature, salinity, and backscatter at $440 \mathrm{~nm}$ and $670 \mathrm{~nm}$ obtained with a Slocum Glider over the same six-day period as in Figure 2. The glider data are not interpolated. Actual data points are plotted as colored picture elements (pixels), with the occasional white speckle indicating data gaps that we have purposely preserved in this case. The ability to directly plot optical and hydrographic cross sections removes ambiguities associated with interpolation schemes (recall the classic Gulf Stream multiple interpretation example of Stommel, 1966). Not included in Figure 3 are plots of density (which everywhere increases with depth despite the temperature and salinity inversions observed offshore), and fluorescence (which is low everywhere, but greatest nearshore). Temperature is nearly uniform across the shelf until the base of the shelfslope front is encountered at the outer edge. The water on the slope side is about $4^{\circ} \mathrm{C}$ colder. Salinity is nearly vertically mixed on the shelf, but instead of being uniform horizontally, it generally increases with distance from the coast. The highest-salinity water is observed in the middle of the water column on the outer edge of the shelf. This high-salinity feature is recognized as an intrusion of warm slope water along the offshore pycnocline, the climatologies of which were recently characterized by Lentz (2003). Backscatter at both wavelengths reveals that the well-mixed, low-salinity water nearshore also supports heavy particle loads. The low NWLR nearshore is likely caused by phytoplankton and detritus. While well offshore, the high-salinity pycnocline intrusion exhibits the lowest backscatter, indicating the smallest particle load.
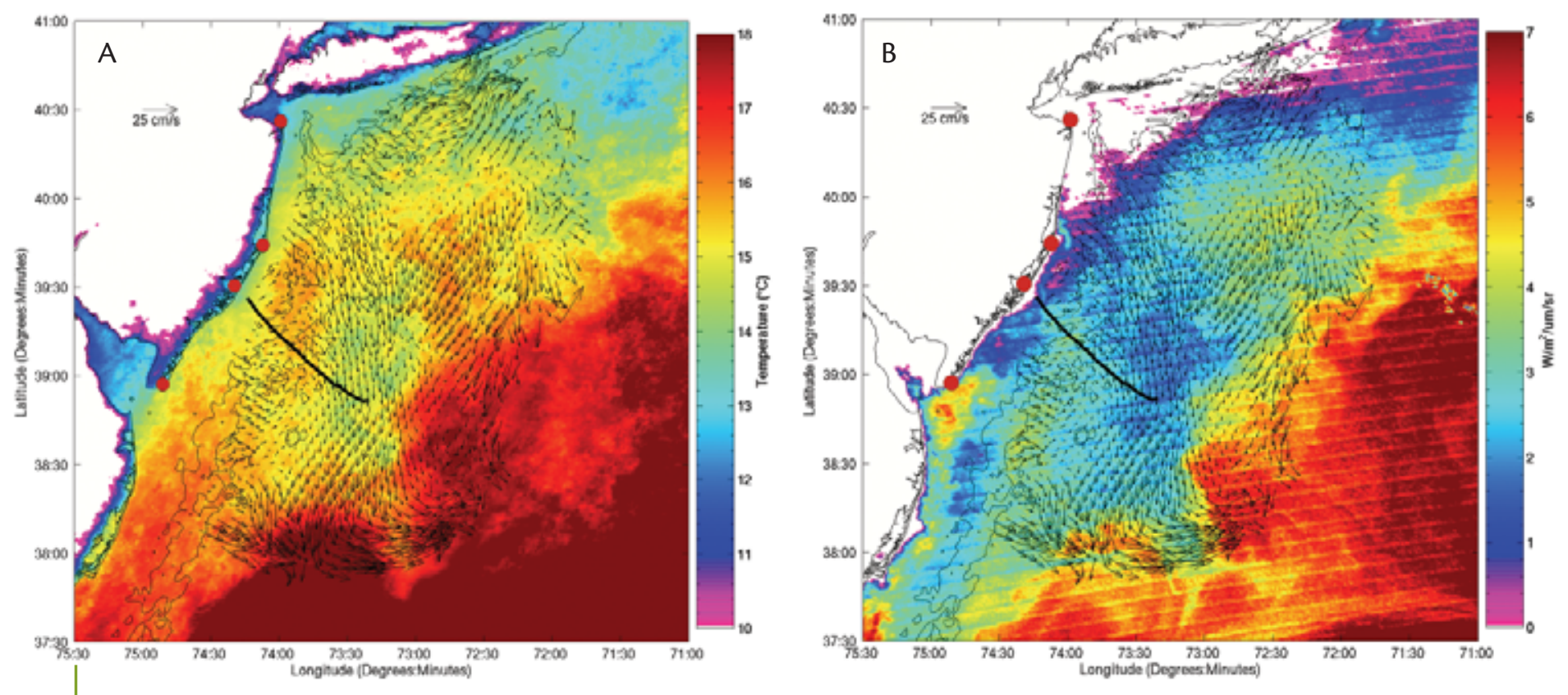

Figure 2. Six-day average surface current vectors (black arrows) from October $28^{\text {th }}$ to November $2^{\text {nd }}, 2003$, overlaid on the (A) six-day satellite-derived sea surface temperature composite and (B) the satellite-derived Normalized Water Leaving Radiance image at the visible wavelength of $443 \mathrm{~nm}$ from October 30, 2003. The black line shows the six-day, crossshelf track of the Slocum Glider as it enters the southward flowing jet located in the middle of the continental shelf. (C) The Slocum Glider is an autonomous underwater vehicle that propels itself through the water by changing its buoyancy. Sensors on board the glider measure temperature, salinity and optical properties over periods of three to four weeks.

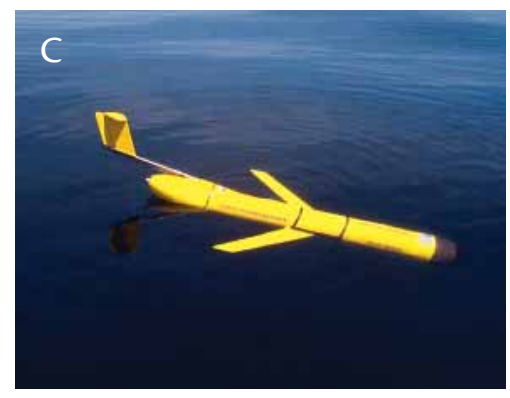


In the middle of the transect where the glider begins to cross the mid-shelf jet observed in Figure 2, a surface-to-mid-depth lens of low backscatter (indicative of low numbers of particles), low-salinity water is encountered. Because of the low particle loads in this jet, increased CDOM concentration is the likely cause of the reduced NWLR in Figure 2, potentially consistent with a Hudson plume source. However, just offshore, a higher-particle-load surface lens is encountered. And just offshore of that, at the end of the glider transect, the very high-salinity, low-particle-load waters from offshore are encountered. The combined satellite, CODAR, and glider data prompt the following questions: Is the cross-shelf transport pathway identified by our data directly associated with the Hudson plume or with some other fresh-water sources (rivers or melted Arctic ice) further to the north? To what extent is the potential Hudson River plume mixing with the other water masses present in the region? Observations from the operational observatory offshore New Jersey prompt questions such as these, which can then be used to motivate hypothesis-driven research on the behavior of the Hudson plume as it encounters wind-driven shelf waters.

The above discussion leaves one dramatic feature of Figure 3 (bottom two panels) unexplained. What is the nature of the two vertical columns of high backscatter located near 74 degrees West Longitude? On either side of these features, large particle loads are observed near the bottom, pointing to local resuspension and nepheloid layers as the cause of high backscatter. But what feature did the glider cross that could possibly contain such high particle loads all the way to the surface when there is no evidence of an advective feature in the satellite image? A quick check of the regional NOAA buoys

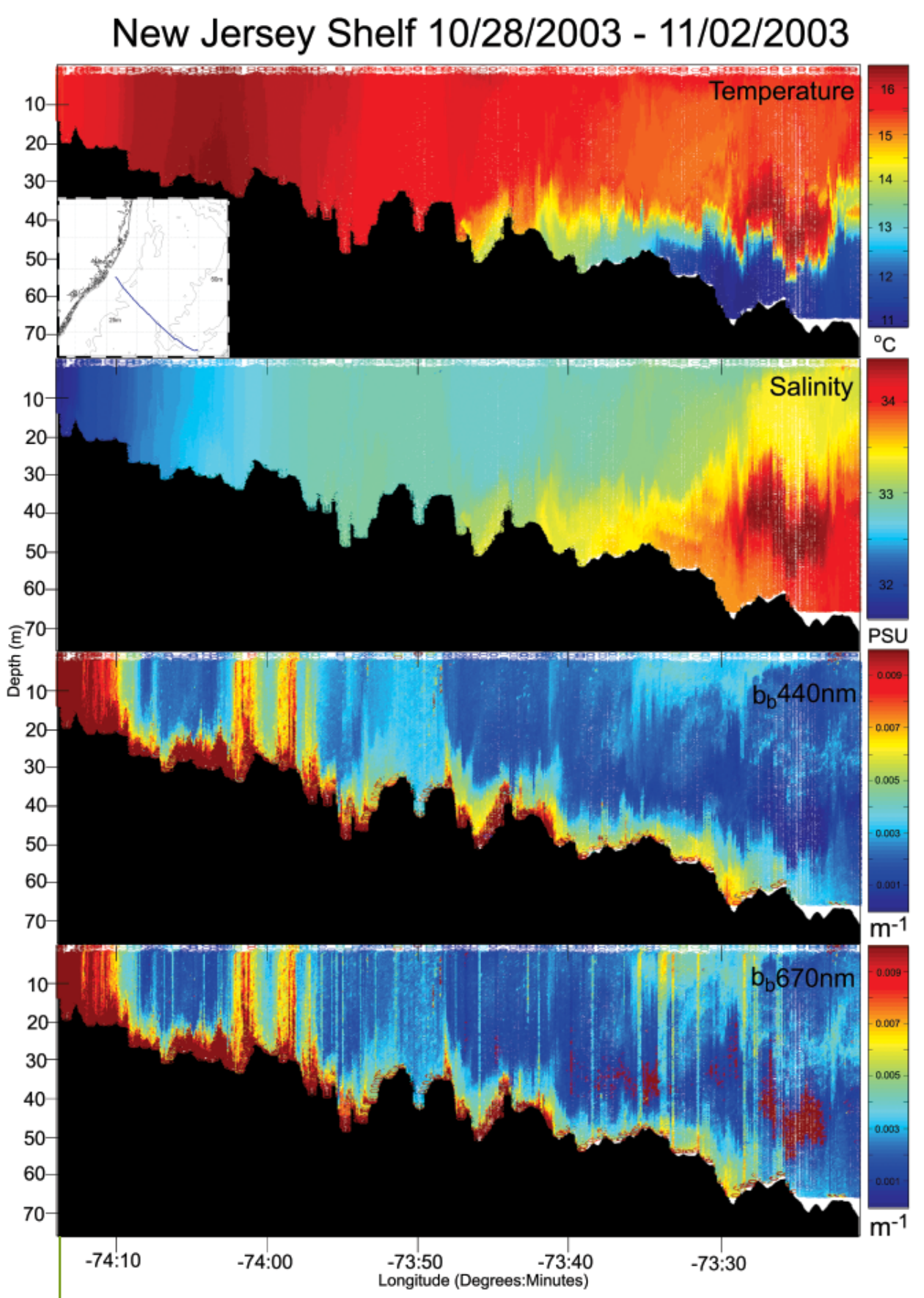

Figure 3. Vertical sections of temperature, salinity, and particle backscatter $\left(b_{b} 440 \mathrm{~nm}\right.$ and $\left.b_{b} 670 \mathrm{~nm}\right)$ at two visible wavelengths measured by the Slocum Glider running along the track shown in Figure 2. The Glider started nearshore on October 28, 2003, in the fresh water with high particle loads and moved offshore through November 2, 2003, into the saltier water with low particle loads. The bottom bathymetry is shaded in black. The inset map shows the location of the track.

indicates that peak storm waves actually preceded the appearance of full water-column particle loads by several hours. One explanation may be that these operational optical observations are another manifestation of the enhanced Langmuir cells recently reported by Gargett and Wells (submitted) based on research acoustic observations at the LEO cabled observatory. Enhanced by potential interactions with the tides and negative surface buoyancy fluxes, the large vertical velocities of these Langmuir cells can 


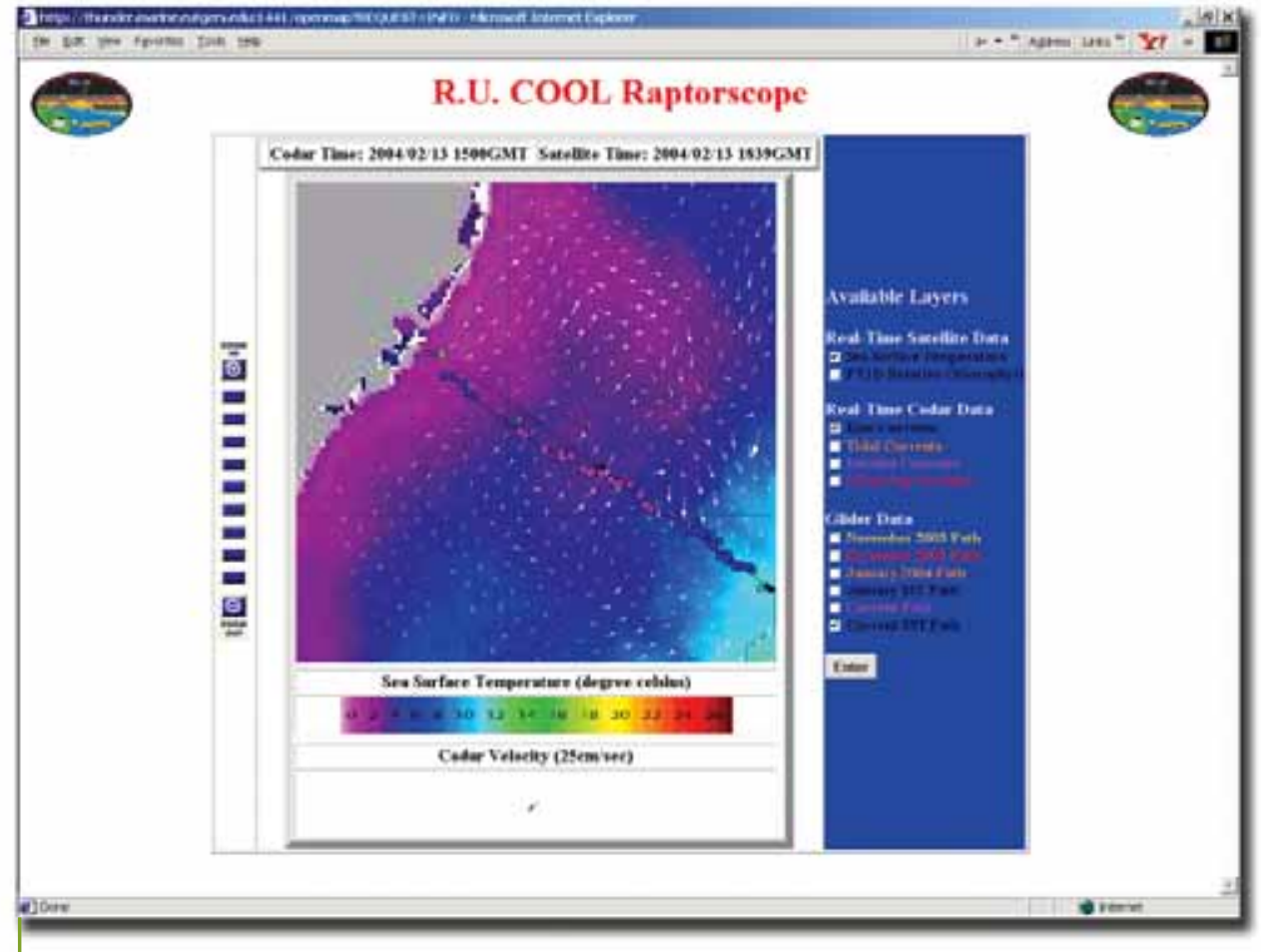

Figure 4. RAPTORscope's view of the coastal ocean off New Jersey. RAPTORscope is a web-based mapping application that enables a user to view and overlay real-time ocean observatory data. Available data layers in the illustration include realtime satellite data (sea surface temperature or chlorophyll), CODAR surface current vectors (raw, tidal, detided, or 3-day averaged), and glider-path data (color coded by surface temperature if desired) from current or past missions. RAPTORscope is named after the RAPidly Triggered Observation Response (RAPTOR) arrays defined at the recent U.S. National Science Foundation Ocean Research Interactive Observatory Networks (ORION) workshop. In this view, a coastal jet is advecting the colder nearshore water offshore.

reach the bottom, resuspend sediment, and rapidly distribute it throughout the water column. Are the optical sensors on the gliders observing the space-time variability of a new sediment resuspension mechanism that now must be parameterized for inclusion in our numerical sediment transport models? Operational sensors on the glider platforms have thus enabled the sensing of particle loads that can then be used to visualize complex flow fields, providing physical oceanographers an additional tool for studying the range of processes active on the continental shelf. is not possible on the shelf-wide scale of NJSOS, and is not consistent with the usual operational concepts where predictive models are run at central facilities away from the on-scene, real-time data collection.

Through innovations in communication (higher-speed Internet-2, global Iridium, wireless) and visualization, it is no longer necessary for all collaborators to be on-scene to participate with an equal sense of purpose in ongoing field activities. Thus NJSOS is beginning to explore the advantages (like sustainability) and challenges (maintaining the sense of purpose) of "virtual" collocation (Olson et al., 2002). Key to this success is the rapid visualization of multiple diverse data sets remotely over the Internet rather than locally as accomplished during the HyCODE years. One step in that direction has been the development of a Web-based system that enables a distributed community to overlay and manipulate real-time mapping data sets from the operational components of the observatory (Figure 4). In the illustrated case, a satellite sea surface temperature image is overlaid with the CODAR surface current vectors and a Slocum Glider track, color coded by water temperature, as it runs just south of a developing offshore jet. Scientists (and others) can manipulate these real-time data as if they were in the same location as those collecting it. Systems such as this, combined with live video and audio feeds, enable scientists at distant locations to participate with the same focused intensity as those working on site.

Another step enabling successful virtual collocation is the emerging ability to extend high-speed Internet connectivity to ships at sea via wireless technologies. The utility of these communications systems to scientists 
was demonstrated during the HyCODE experiments. Researchers on shore could plot and then visualize the same data being collected by the ships at sea in real-time. Researchers at sea could use the real-time data collected by the observatory to place their local data in the broader spatial context. Sampling plans could be modified based on the rapidly evolving ocean features, maximizing the efficiency of time at sea.

NJSOS is now the site of the National Science Foundation (NSF) Lagrangian Transport and Transformation Experiment (LaTTE), an interdisciplinary study of the Hudson River plume. LaTTE is a prime example of a process study conducted within the spatial and temporal context provided by an academic operational observatory. In New Jersey terms, if the sustained NJSOS data set has identified a potential cross-shelf transport highway, LaTTE will be a study of the "on ramp" to this highway. Yet, consistent with the research, education, and outreach missions of the State University of New Jersey, the observatory remains multi-use, simultaneously contributing to fisheries efforts to better understand the transport of fish larvae, efforts to improve Search And Rescue techniques, efforts to track vessels for security-related purposes, efforts to monitor the ocean influence on seabreeze for energy issues, and education and outreach efforts for the K-12 community. As we proceed through this critical stage of our nation's observatory development, let us remember the synergies created by the collaborative experiences reported here, and encourage these concepts to be integrated into the planning process as we build both sustainable and innovative operational systems for the multiuse needs of the future.

\section{ACKNOWLEDGEMENTS}

The lessons learned from HyCODE go well beyond technical development and scientific accomplishments. They address the developing culture of interdisciplinary scientific collaboration. We thank all the funding agencies and participants for trusting us to be part of it.

\section{REFERENCES}

Chant, R.J., S.M. Glenn, and J. Kohut, in press: Flow reversals during upwelling conditions on the New Jersey inner shelf. J. Geophys. Res.

Curtin, T.B., J.G. Bellingham, J. Catipovic, and D. Webb, 1993: Autonomous oceanographic sampling networks. Oceanography, 6(3), 86-94.

Dickey, T.D., 2003: Emerging ocean observations for interdisciplinary data assimilation systems. Journal of Marine Systems, 40-41, 5-48.

Dickey, T.D., G.C. Chang, Y.C. Agrawal, A.J. Williams, III, and P.S. Hill, 1998: Sediment resuspension in the wakes of Hurricanes Edouard and Hortense. Geophysical Research Letters, 25, 3,533-3,536.

Dickey, T., S. Zedler, X. Yu, S.C. Doney, D. Frye, H. Jannasch, D. Manov, D. Sigurdson, J.D. McNeil, L. Dobeck, T. Gilboy, C. Bravo, D.A. Siegel, and N. Nelson, 2001: Physical and biogeochemical variability from hours to years at the Bermuda Testbed Mooring site: June 1994 - March 1998. Deep-Sea Res. II, 48 (8-9), 2,105-2,140.

Gargett, A., and J. Wells, submitted. Langrangian supercells: A dominant mechanism for sediment resuspension and transport in shallow shelf areas. Science.

Glenn, S.M., W. Boicourt, B. Parker, and T.D. Dickey, 2000a. Operational observation networks for ports, a large estuary and an open shelf. Oceanography, 13, 12-23.

Glenn, S.M., T.D. Dickey, B. Parker, and W. Boicourt, 2000b: Long-term real-time coastal ocean observation networks. Oceanography, 13, 24-34.

Glenn, S.M., and O. Schofield, 2003: Observing the oceans from the COOLroom: Our history, experience, and opinions. Oceanography, 16(4), 37-52.

Harris, C.K., B. Butman, and P. Traykovski, 2003: Wintertime circulation and sediment transport in the Hudson Shelf Valley. Continental Shelf Res., 23(8), 801-820.
Helland-Hansen, B., 1916: Nogen hydrografiske metoder form. skand. Naturf. Mote, 357-359.

Johnson, D.R., and J. Miller, 2003: Dynamics and optics of the Hudson River outflow. J. Geophys. Res., 108(C10), 3,323, doi:10.1029/2002JC001485.

Lentz, S.J., 2003: A climatology of salty intrusions over the continental shelf from Georges Banks to Cape Hatteras. J. Geophys. Res., 108(C10), 24-1-24-12.

Ofiara, D., and J. Seneca, 2001: Economic Losses from Marine Pollution: A Handbook for Assessment. Island Press, Washington, D.C., 388 pp.

Olson, J.S., S.D. Teasley, L. Covi, and G.M.S. Olson, 2002: The currently unique advantages of collocated work. In: Distributed Work, P. Hinds and S. Kiesler, eds. MIT Press, Cambridge, MA.

Rudnick, D.L., and M.J. Perry, eds., 2003: ALPS: Autonomous and Lagrangian Platforms and Sensors, Workshop Report, 64 pp., Available on-line at: http://www. geo-prose.com/ALPS.

Schofield, O., T. Bergmann, W.P. Bissett, F. Grassle, D. Haidvogel, J. Kohut, M. Moline, and S. Glenn, 2002: Linking regional coastal observatories to provide the foundation for a national ocean observation network. I.E.E.E. J. of Ocean. Eng., 27(2), 146-154.

Stommel, H., 1966: The Gulf Stream A Physical and Dynamical Description, 2nd Edition. University of California Press, Berkeley California, 248 pp.

Teasley, S., L. Covi, M.S. Krishnan, J.S. Olson, 2000: How does radical collocation help a team succeed? Pp. 339-346 in Proceedings of the 2000 ACM conference on Computer supported cooperative work, ACM Press, New York.

Tomczak, M., 1999: Potential vorticity as a tracer in quantitative water mass analysis. International WOCE Newsletter 36, 6-10.

Wilkin, J.L., H.G. Arango, D.B. Haidvogel, S.K. Hedstrom, C.S. Lichtenwalner, and S.M. Glenn, submitted: A regional ocean modeling system for the Longterm Ecosystem Observatory. J. Geophys. Res. - NEOS Special Section. 